\title{
VARIABLE STRUCTURE SLIDING MODE CONTROL AND DIRECT TORQUE CONTROL OF WIND POWER GENERATION SYSTEM BASED ON THE PM SYNCHRONOUS GENERATOR
}

\author{
Youssef Errami ${ }^{*}$ - Mohammed Ouassaid ${ }^{* *}$ \\ Mohamed Cherkaoui $^{\text {** }}$ - Mohamed Maaroufi ${ }^{* *}$
}

\begin{abstract}
This paper presents a Variable Structure Sliding Mode Control (VS-SMC) scheme and Direct Torque Control (DTC) for Wind Farm (WF) based on the Permanent Magnet Synchronous Generator (PMSG). The WF consists of a 3 PMSGs which are connected to a common dc bus system with rectifier. The dc-bus is connected to the electrical network using only one inverter system, a grid-side filter as well as the transformer. The efficiency of the WF can be greatly improved using an appropriate control approach. So, the control strategy uses the technique of DTC to regulate the speeds of PMSGs for Maximum Power Point Tracking (MPPT) mode. Besides, by employing VS-SMC the grid-side inverter is controlled to inject the generated power into the electrical network, to regulate DC-link voltage and to achieve Unity Power Factor. The used control strategies provide an optimal control solution for WF systems based on the PMSG.
\end{abstract}

K e y w o r d s: wind power generation system, PMSG, MPPT, VS-SMC, DTC, unity power factor

\section{INTRODUCTION}

In recent years, considerable progress has been made to use diverse types of renewable energy sources [1]. Particularly, wind energy has been paid greatly attention owing to the energy shortage and environmental worry [2]. On the other hand, variable speed wind generation system (VS-WGS) has different advantages over fixed-velocity generation system, such as lower mechanical stress, less power fluctuation, operation at maximum power point tracking (MPPT) and increased energy capture. So, VSWGS is becoming the most important and fastest increasing application of wind generation system [3]. In terms of the VS-WGS, wind systems with permanent magnet synchronous generator (PMSG) become very attractive because of their high efficiency, low maintenance requirements, better controllability, high power density, and improved reliability thanks to the absence of gearboxes. Also, PMSG do not necessitate electrical excitation. Consequently, with those advantages, PMSG has been considered a promising candidate for novel designs in VS-WGS [4-6]. Hence, usually system with a PMSG is connected to the grid via an AC-DC-AC converter and, the VS-WGS doesn't need to synchronize its rotational velocity with the grid frequency [7]. For this reason, the power control of VS-WGS is receiving considerable interest around the world. In this context, this paper proposes a novel direct torque control (DTC) and variable structure sliding mode control (VS-SMC) scheme for Wind Farm (WF) based on the PMSGs. The block diagram of proposed WF is shown in Fig. 1. Each generator of the farm is connected to the DC-bus through a rectifier, but the DC-bus is connected to the grid through only one DC/AC inverter. The efficiency of the variable speed farm can be greatly improved using an appropriate control method. So, several control schemes have been proposed for WECS. They consist of two back-to-back PWM converters with a common DC-link. On the other hand, control algorithm based on the Vector Control (VC) strategy has been investigated for both converters with PI control, where decoupling control of active current and reactive current is fundamental [8-10]. Then, the direct torque control (DTC) strategy is an alternative to $\mathrm{VC}$ for PMSG used in WECS. The DTC technique is to control both the torque and the stator flux of PMSG, at the same time during one control period, by selecting appropriate stator voltage vector [11].

Many studies have examined DTC of permanent magnet synchronous motors (PMSM) [12-13]. Generally, when compared to VC, DTC possesses several advantages like: the control is without using current loops, a pulse width modulation (PWM) modulator is not used, the control does not require coordinate transformation between the stationary frame and synchronous frame, as in the conventional VC, and DTC minimizes the use of machine parameters, then it is little sensible to the parameters variation. Furthermore, the WF is connected to the grid through only one DC/AC inverter. The objectives of grid-side converter are to deliver the energy from the PMSGs sides to the utility grid, to regulate the DC-

\footnotetext{
* University Chouaib Doukkali, Department of Physical Faculty of Science, Laboratory of Electronics, Instrumentation and Energy, Team: Exploitation and Processing of Renewable Energy, Eljadida, Morocco ** Department of Electrical Engineering, Mohammadia School's of Engineers, University Mohammed V., Rabat, Morocco, errami.emi@gmail.com
} 


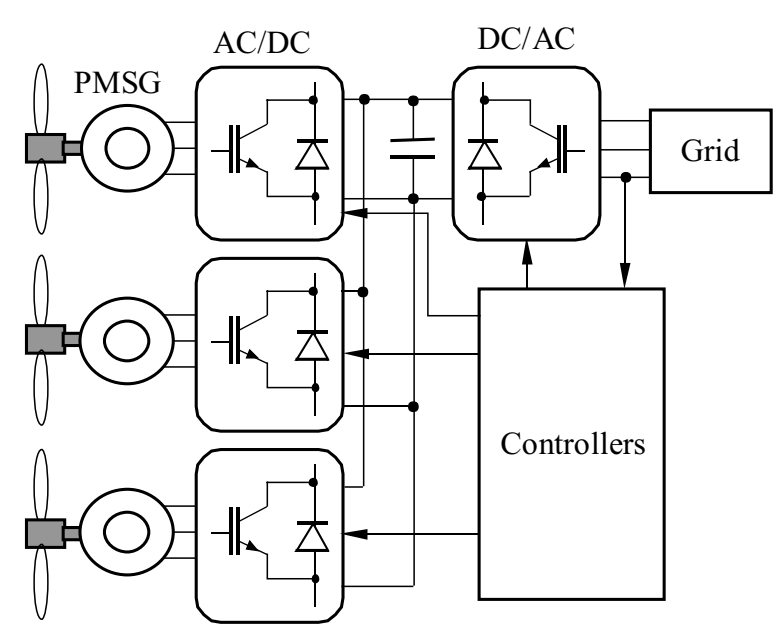

Fig. 1. Block diagrams of Wind Farm

link voltage regardless of the wind speed and to achieve unity power factor. So, several control schemes have been proposed for grid side converter such as Vector Control (VC) and direct power control (DPC) [14-15]. Besides, the $\mathrm{VC}$ is based on Proportional Integral (PI) controller. Decoupling control of active current and reactive current is required and reactive and active powers are controlled respectively by the converter. However, the main disadvantage for this control strategy is that the performance highly relies on the connected grid voltage conditions, the accurate tuning of PI parameters and the completeness of current decoupling. Accordingly, DPC was developed for the control of grid connected inverter and it was an alternative control approach. This strategy is based on the principles of Direct Torque Control (DTC) and uses, for the optimal switching table, the virtual flux vector which is the integration of the converter voltage, the angular position of the converter voltage vectors or with constant switching frequency in order to regulate the inverter [16]. The major advantage of this approach is that it does not need neither coordinate transformations, nor linear current controller nor modulators. Recently, sliding mode control (SMC) which is based on the variable structure control (VSC) method can be used to accommodate the effects of uncertainties and to provide an effective method of improving the robustness of the control system against parameter variation. Moreover, VSC approach is insensible to external trouble and variations of WF parameters with a minimum of implementation complexity [17]. Then, for power controller, [18] propose the nonlinear SMC scheme below the rated wind velocity to maximize the generated power and, [19] introduce high order sliding mode controllers so as to reduce the chattering effect. Consequently, SMC is an attractive choice for control of grid-connected dc/ac converters.

For these reasons, this paper deals with the control strategy combines the technique of maximum power point tracking (MPPT) method and DTC in speeds controllers to achieve optimal control of the WF, while SMC approach is used for grid inverter to regulate the DC-link voltage and to achieve unity power factor. Also, the stability of the controller is guaranteed using Lyapunov analysis.

The remainder of this paper is organized as follows: Section 2 gives the models of the individual wind turbine generator and PMSG. In Section 3, control of WF will be presented. Section 4 presents and discusses the simulation results. Finally, some conclusions are given in Section 5.

\section{MODELING OF WF}

\subsection{Wind turbine characteristic}

Output aerodynamic power of the wind-turbine is expressed as [9]

$$
P_{\text {Turbine }}=\frac{1}{2} \rho A C_{P}(\lambda, \beta) v^{3}
$$

where, $\rho$ is the air density, $A$ is the area swept by the rotor blades (in $\mathrm{m}^{2}$ ), $v$ is the wind speed (in $\mathrm{m} / \mathrm{s}$ ), $C_{P}$ is the coefficient of power conversion and $\beta$ is the blade pitch angle (in degrees) . The tip-speed ratio is defined as $[9]$

$$
\lambda=\frac{\omega_{t} R}{v}
$$

where $\omega_{t}$ and $R$ are the shaft speed (in $\mathrm{rad} / \mathrm{sec}$ ) and rotor radium (in $\mathrm{m}$ ), respectively. The torque output of the wind turbine $T_{m}$ is given by

$$
T_{m}=\frac{1}{2} \rho A C_{P}(\lambda, \beta) v^{3} \frac{1}{\omega_{t}} .
$$

The turbine is coupled to the generator through a gearbox. Then: $\omega_{m}=G \omega_{t}$ where $\omega_{m}$ and $G$ are the rotor angular velocity and the gear ratio, respectively. The power coefficient $C_{P}$ is a nonlinear function of $\beta$ and the tip-speed ratio $\lambda$. If the swept area of the blade and the air density are constant, the value of $C_{P}$ is a function of $\lambda$ and it's maximum at the particular $\lambda_{o p t}[10]$. For this reason, in order to fully utilize the wind energy, $\lambda$ should be maintained at $\lambda_{\text {opt }}$, which is determined from the blade design.

A generic equation is used to model the power coefficient $C_{P}(\lambda, \beta)$ based on the modeling turbine characteristics described in [10] as

$$
\begin{aligned}
C_{P} & =\frac{1}{2}\left(\frac{116}{\lambda_{i}}-0.4 \beta-5\right) e^{-\frac{21}{\lambda_{i}}} \\
\frac{1}{\lambda_{i}} & =\frac{1}{\lambda+0.08 \beta}-\frac{0.035}{\beta^{3}+1}
\end{aligned}
$$

The maximum value of $C_{P}(\lambda, \beta)$, that is $C_{P_{\max }}=0.41$, is achieved for $\beta=0^{\circ}$ and for $\lambda_{\text {opt }}=8.1$. This particular value $\lambda_{\text {opt }}$ results in the point of optimal efficiency where the maximum power is captured from wind by the wind turbine.

$$
P_{\text {Turbine }}=\frac{1}{2} \rho A C_{P_{\max }} v^{3} .
$$




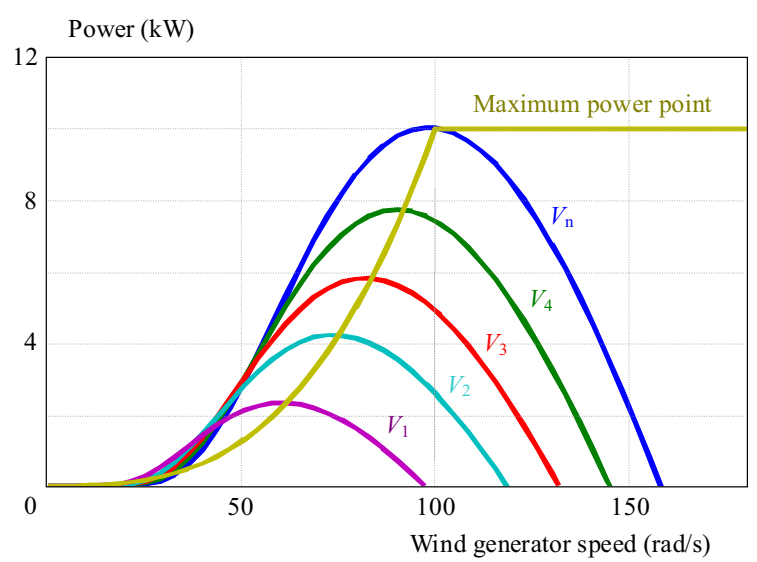

Fig. 2. Wind generator power curves at various wind speed

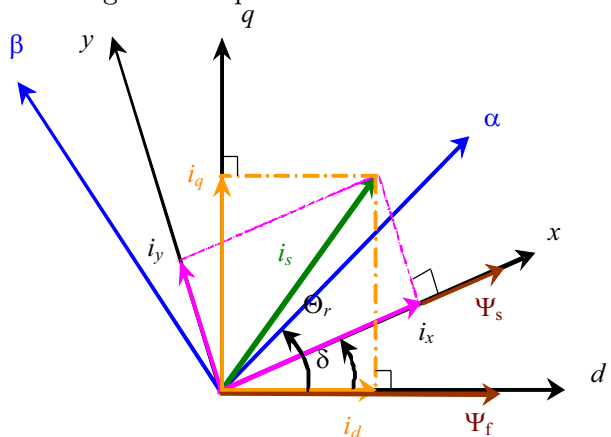

Fig. 3. The stator and rotor flux linkages in various reference frames

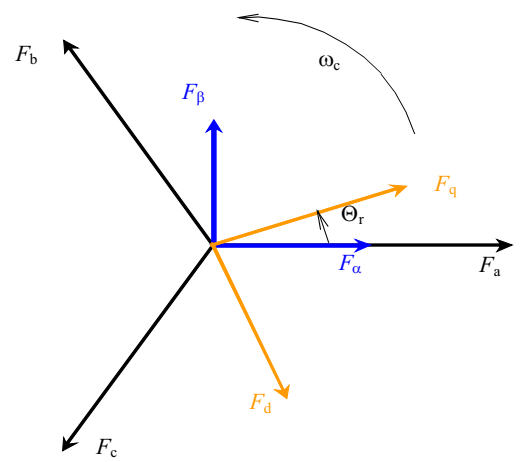

Fig. 4. abc and rotating reference frame

Consequently, for each wind speed, there exists a specific point in the wind generator power characteristic, MPPT, where the extracted power is maximized. Then, if the PMSG can operate in the optimal rotational speed $\omega_{\text {opt }}$, the system can operate at the peak of the power curves at various wind speed and the maximum extracted power can be achieved. That is shown in Fig. 2. Hence, the curve connecting the peaks of these curves will generate the maximum output power (MPP) for a given wind speed and follows the path for maximum power operation.

\subsection{PMSG model}

The stator magnetic flux vector $\psi_{s}$ and the rotor magnetic flux vector $\psi_{f}$ can be drawn in the rotor flux $(d-q)$, stator flux $(x-y)$ and stationary $(\alpha-\beta)$ frames. The various reference frames are shown in Fig. 3 where $\delta$ is the load angle that's constant for a certain load torque and $\theta_{r}$ is the rotor angle.
Both stator and rotor flux rotate at synchronous speed. The generator equations in the $d-q$ reference frame are

$$
\begin{gathered}
v_{g d}=R_{g} i_{d}+\frac{\mathrm{d}}{\mathrm{d} t} \psi_{s d}-\omega_{e} \psi_{s q}, \\
v_{g q}=R_{g} i_{q}+\frac{\mathrm{d}}{\mathrm{d} t} \psi_{s q}+\omega_{e} \psi_{s d}, \\
\psi_{s d}=L_{d} i_{d}+\psi_{f}, \quad \psi_{s q}=L_{q} i_{q} .
\end{gathered}
$$

The electrical rotating speed of the generator, $\omega_{e}$, is defined by

$$
\omega_{e}=p_{n} \omega_{m}
$$

Thus

$$
\begin{aligned}
& v_{g d}=R_{g} i_{d}+L_{d} \frac{\mathrm{d} i_{d}}{\mathrm{~d} t}-\omega_{e} L_{q} i_{q}, \\
& v_{g q}=R_{g} i_{q}+L_{q} \frac{\mathrm{d} i_{q}}{\mathrm{~d} t}+\omega_{e} L_{d} i_{d}+\omega_{e} \psi_{f} .
\end{aligned}
$$

The expression for the electromagnetic torque can be described as

$$
T_{e}=\frac{3}{2} p_{n}\left[\psi_{s d} i_{q}-\psi_{s q} i_{d}\right]
$$

In addition, the dynamic equation of the wind turbine is given as

$$
J \frac{\mathrm{d} \omega_{m}}{\mathrm{~d} t}=T_{e}-T_{m}-F \omega_{m}
$$

where $J$ is the total moment of inertia of the system, $F$ is the viscous friction coefficient and $T_{m}$ is the mechanical torque developed by the turbine.

These equations can be transformed by using Clarke transformation (15): $a b c \rightarrow \alpha-\eta$, Park Transformation (16) $\alpha-\beta \rightarrow d-q$ and the vector representation shown in Fig. 4.

$$
\begin{gathered}
\left(\begin{array}{c}
\alpha \\
\beta
\end{array}\right)=\frac{2}{3}\left[\begin{array}{lll}
1 & \cos (2 \pi / 3) & \cos (4 \pi / 3) \\
0 & \sin (2 \pi / 3) & \sin (4 \pi / 3)
\end{array}\right]\left(\begin{array}{l}
a \\
b \\
c
\end{array}\right) \\
\left(\begin{array}{l}
d \\
q
\end{array}\right)=\left[\begin{array}{cc}
\cos \left(\theta_{r}\right) & \sin \left(\theta_{r}\right) \\
-\sin \left(\theta_{r}\right) & \cos \left(\theta_{r}\right)
\end{array}\right]\left(\begin{array}{l}
\alpha \\
\beta
\end{array}\right)
\end{gathered}
$$

Thus, transformation

$$
\left(\begin{array}{c}
E_{x} \\
E_{y}
\end{array}\right)\left[\begin{array}{cc}
\cos \delta & \sin \delta \\
-\sin \delta & \cos \delta
\end{array}\right]\left(\begin{array}{c}
E_{d} \\
E_{q}
\end{array}\right)
$$

is obtained, where $E$ represents the current, voltage or magnetic flux.

Moreover, equation (18) can be obtained

$$
\cos \delta=\frac{\psi_{s d}}{\left|\psi_{s}\right|}, \quad \sin \delta=\frac{\psi_{s q}}{\left|\psi_{s}\right|} .
$$




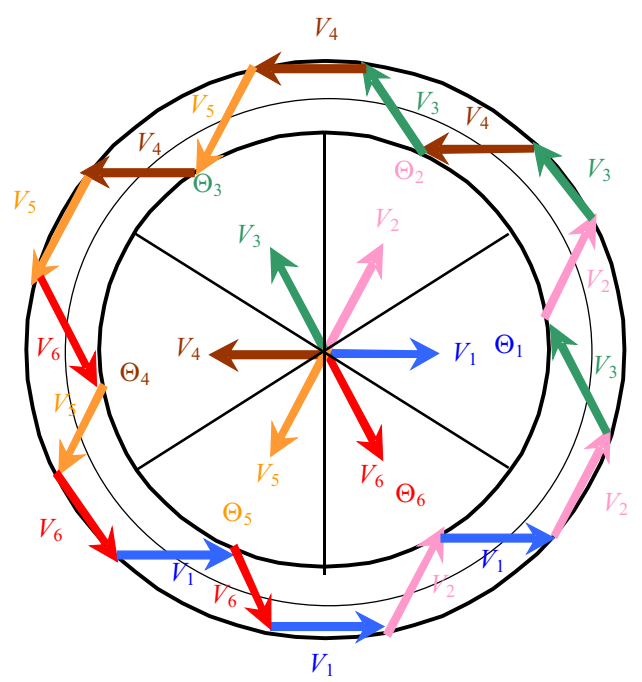

Fig. 5. The control of stator flux linkage

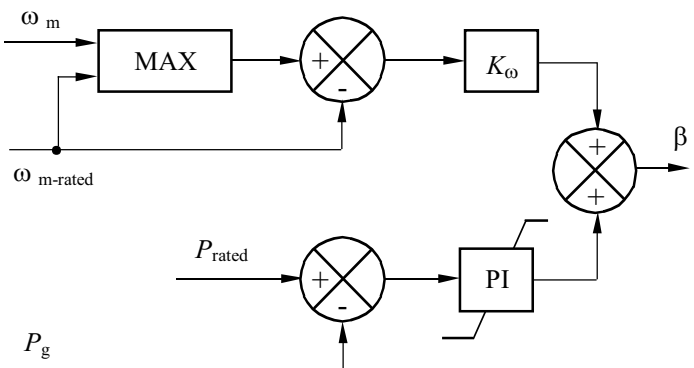

Fig. 6. WECS Pitch angle controller

Then, using equations (13), (17) and (18) the torque $T_{e}$ of PMSG in the $x-y$ reference frame is given by

$$
T_{e}=\frac{3}{2} p_{n}\left|\psi_{s}\right| i_{y}
$$

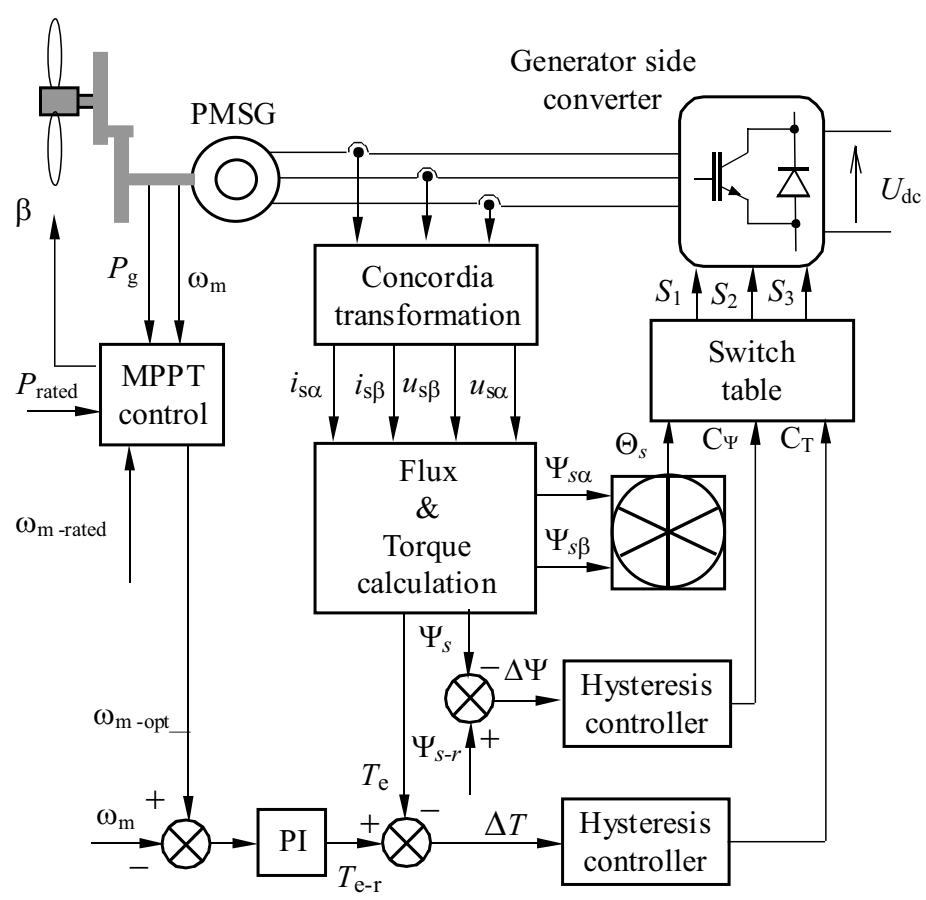

Fig. 7. Block diagram of individual machine side converter controller component of stator current. expressed as has $\psi_{s y}=0$. Then by stator flux linkage $\psi_{s}$ constant. voltage vectors is given by

where $\psi_{s 0}$ is the initial stator flux. tion (24) over a short time period.

\section{Generator side}

Accordingly, from (19), if the amplitude of the stator flux linkage can be constantly controlled, we can deduce that the torque of PMSG is directly proportional to the $y$-axis

For salient pole PMSG, $L_{q}=L_{d}=L_{s}$ and the torque flux linkage of PMSG in the $\mathrm{x}-\mathrm{y}$ reference frame can be

$$
\left(\begin{array}{c}
\psi_{s x} \\
\psi_{s y}
\end{array}\right)=\left[\begin{array}{cc}
L_{s} & 0 \\
0 & L_{s}
\end{array}\right]\left(\begin{array}{c}
i_{x} \\
i_{y}
\end{array}\right)+\psi_{f}\left(\begin{array}{c}
\cos \delta \\
-\sin \delta
\end{array}\right) .
$$

When the stator flux linkage oriented to the $x$ axis, it

$$
i_{y}=\frac{1}{L_{s}} \psi_{f} \sin \delta .
$$

Then, using equations (19) and (21) the torque $T_{e}$ is given

$$
T_{e}=\frac{3}{2 L_{s}} p_{n}\left|\psi_{s}\right| \psi_{f} \sin \delta .
$$

Consequently, from (22), it is possible that the torque of the PMSG is controllable by regulating the torque angle $\delta$ under the condition of keeping the amplitude of the

Furthermore, the relation between the stator flux and

$$
\psi_{s}=\psi_{s 0}+\int_{0}^{t}\left(v_{s}-R_{g} i_{s}\right) \mathrm{d} t
$$

If the stator resistance is ignored, then the stator flux, as given in equation (23), can be approximated as equa-

$$
\psi_{s}=\psi_{s 0}+\int_{0}^{t} v_{s} \mathrm{~d} t .
$$

$$
u_{k}
$$




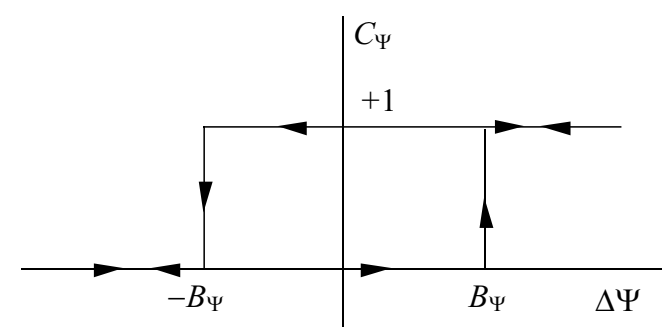

Fig. 8. Stator flux hysteresis comparator

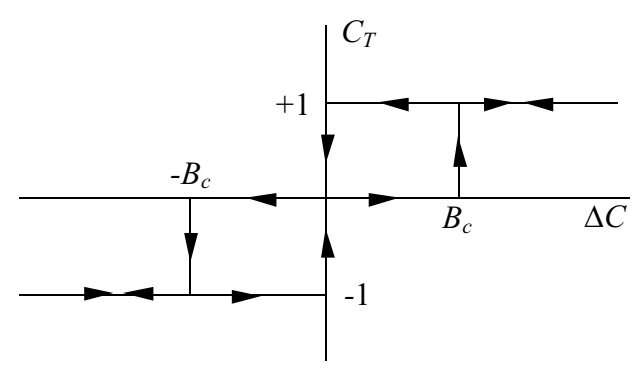

Fig. 9. Torque hysteresis comparator

Besides, during one period of the control algorithm $T_{s}$, voltage vector applied to the machine, remains constant. Thus

$$
\psi_{s}(k+1)=\psi_{s}(k)+v_{s} T_{s}
$$

where $\psi_{s}(k+1)$ and $\psi_{s}(k)$ are the stator flux vectors at the sampling times $(k+1) T_{s}$ and $k T_{s}$, respectively.

Relation (25) leads to

$$
\Delta \psi_{s}=v_{s} T_{s}
$$

is the stator flux variation vector.

As a result, according to (26), the variation of the stator flux vector is achieved through the application of the appropriate stator voltage $v_{s}$. The stator flux vector rotates in the same direction as the applied stator voltage vector and with a rotation speed proportional to the stator voltage magnitude. Hence, by adequate voltage vector selection, we can decrease or increase the stator flux phase and amplitude to obtain the required performances. Also, the choice of the voltage vector depends on the position of the flux vector.

Moreover, voltage vector plane is divided into six sectors as shown in Fig. 5, and two adjacent vectors are selected in order to increase or decrease the amplitude respectively. There are eight voltage vectors $\left(V_{i}\right.$, $i=0,1,2, \ldots, 7)$ available for the voltage source rectifier. Among them, there are two zero voltage vectors $\left(V_{i}, \quad i=0,7\right)$ and six nonzero voltage vectors $\left(V_{i}\right.$, $i=1,2,3, \ldots, 6)$. Consequently, when the stator magnetic flux is moved clockwise in sector 2, voltage space vector $V_{4}$ is selected so as to decrease the amplitude voltage and space vector $V_{3}$ is selected in order to increase the stator magnetic flux amplitude. When the stator magnetic flux moves clockwise, if still in sector $2, V_{1}$ is used to increase the amplitude and $V_{6}$ is used to decrease the amplitude. The torque of the PMSG can be controlled using DTC by means of controlling the stator magnetic flux rotation speed in case the stator magnetic flux amplitude is kept constant.

\section{WIND FARM CONTROL STRATEGY}

\subsection{Adopted MPPT control algorithm}

For each Wind Turbine Generator (WTG), the objective of the MPPT controller is to generate the reference velocity command which will enable the WTG to extract maximum power from the available wind power. Moreover, for any particular wind speed, the optimal rotational velocity of the WTG can be simply estimated as

$$
\omega_{m-o p t}=\frac{v \lambda_{o p t} G}{R} .
$$

The MPPT controller computes this optimum speed and an optimum value of tip speed ratio $\lambda_{o p t}$ can be maintained then maximum wind power, of the WTGs, can be extracted. So, the maximum mechanical output power of the turbine is given as

$$
P_{\text {Turbine } \max }=\frac{1}{2} \rho A C_{P_{\max }}\left(\frac{R \omega_{m-o p t}}{\lambda_{o p t}}\right)^{3} .
$$

Consequently, we can get the maximum power

$P_{\text {Turbine max }}$ by regulating the WTG speed in different wind speed under rated power of the WF system.

\subsection{Pitch controller}

When wind velocity is low or medium, the pitch angle is controlled to permit the individual WTG to operate at its optimum condition. The pitch controller is only active in high wind speeds, to prevent the rotor speed from becoming too high. Accordingly, when the wind velocity reaches the nominal value, the pitch angle controller enters in operation to decrease the coefficient of power for each WTG. So, the blade pitch angle, $\beta$, will increase until the wind turbine is at the rated speed. Fig. 6 depicts the implemented turbine blade pitch angle controller where $P_{g}$ is the generated power.

\subsection{Control strategy for generator sides convert- ers with MPPT and DTC}

For each PMSG, the generator side three phase converter is used as a rectifier with a DTC strategy. Figure 7 depicts the implemented block diagram of the generator controller. The adopted MPPT controller generates $\omega_{m_{-} \text {opt }}$, the reference speed. The generator is controlled based on DTC algorithm. Besides, generator torque reference is derived based on MPPT strategy and PI controller is used to regulate the speed of PMSG.

The equivalent two-phase stator voltages along the stationary $\alpha-\beta$ axis are obtained as follows

$$
\begin{aligned}
& u_{s \alpha}=\frac{U_{d c}}{3}\left(2 S_{1}-S_{2}-S_{3}\right), \\
& u_{s \beta}=\frac{U_{d c}}{\sqrt{3}}\left(S_{2}-S_{3}\right)
\end{aligned}
$$


where $U_{d c}$ is the DC-bus voltage and $\left(S_{1}, S_{2}, S_{3}\right)$ the switching states of the rectifier. The voltage vectors obtained this way are shown in Fig. 5.

The $\alpha-\beta$ components of the stator current are calculated using equation (15)

$$
\begin{gathered}
i_{s \alpha}=i_{s a}, \\
i_{s \alpha}=\frac{i_{s a}+2 i_{s b}}{\sqrt{3}} .
\end{gathered}
$$

The components of the stator flux linkage, in the stationary reference frame, are

$$
\begin{aligned}
& \psi_{s \alpha}=\int\left(u_{s \alpha}-R_{g} i_{s \alpha}\right) \mathrm{d} t, \\
& \psi_{s \beta}=\int\left(u_{s \beta}-R_{g} i_{s \beta}\right) \mathrm{d} t .
\end{aligned}
$$

The flux amplitude and its phase are derived respectively from

$$
\begin{aligned}
\psi_{s} & =\sqrt{\psi_{s \alpha}^{2}+\psi_{s \beta}^{2}}, \\
\theta_{s} & =\operatorname{arctg} \frac{\psi_{s \beta}}{\psi_{s \alpha}} .
\end{aligned}
$$

The electromagnetic torque is expressed as

$$
T_{e}=\frac{3}{2} p_{n}\left[\psi_{s \alpha} i_{s \beta}-\psi_{s \beta} i_{s \alpha}\right] .
$$

Furthermore, the DTC strategy is based on two discrete hysteresis comparators in which the stator flux and the torque are controlled directly. The basic principle is that the errors of flux and electromagnetic torque that exist between the reference and feedback values are inputs to the hysteresis controllers as shown in Figs. 8 and 9 so as to select appropriate voltage vector with the help of a predefined switching table as shown in Table 1 . The output of these comparators $\left(C_{\psi}, C_{T}\right)$ and the position of stator flux linkage space vector $\left(\theta_{s}\right)$ are the three inputs of this switching table. Consequently, the vector of voltage makes the flux rotates and produces the desired torque. Also, with comparators, the amplitude of the flux is kept in a pre-defined band.

Table 1. Switching vectors

\begin{tabular}{cccccccc}
\hline$C_{\Psi}$ & $C_{T}$ & $\Theta_{1}$ & $\Theta_{2}$ & $\Theta_{3}$ & $\Theta_{4}$ & $\Theta_{5}$ & $\Theta_{6}$ \\
\hline \multirow{4}{*}{0} & 1 & $V_{3}$ & $V_{4}$ & $V_{5}$ & $V_{6}$ & $V_{1}$ & $V_{2}$ \\
& 0 & $V_{0}$ & $V_{7}$ & $V_{0}$ & $V_{7}$ & $V_{0}$ & $V_{7}$ \\
& -1 & $V_{5}$ & $V_{6}$ & $V_{1}$ & $V_{2}$ & $V_{3}$ & $V_{4}$ \\
\hline \multirow{3}{*}{1} & 1 & $V_{2}$ & $V_{3}$ & $V_{4}$ & $V_{5}$ & $V_{6}$ & $V_{1}$ \\
& 0 & $V_{7}$ & $V_{0}$ & $V_{7}$ & $V_{0}$ & $V_{7}$ & $V_{0}$ \\
& -1 & $V_{6}$ & $V_{1}$ & $V_{2}$ & $V_{3}$ & $V_{4}$ & $V_{5}$ \\
\hline
\end{tabular}

\subsection{Grid-Side Controller Methodology}

The configuration of the WF used for this study is shown in Fig. 10. It consists of 3 PMSGs based 10KW generators connected to a common DC-bus. Each PMSG of the WF is connected to the DC-bus through a rectifier, but the DC-bus is connected to the grid through only one $\mathrm{DC} / \mathrm{AC}$ inverter. The objectives of grid-side inverter are to deliver the energy from the PMSG sides to the utility grid, to regulate the DC-link voltage and to achieve unity power factor during wind variation. There are many methods used to control grid side converter [9]. In this study, the Variable Structure (VS) controllers are adopted to regulate the output voltage and currents in the inner control loops and the DC bus controller in the second loop (Fig. 10). Hence, it can regulate instantaneous values of reactive power and active power of grid connection, respectively.

The voltage balance across the inductor $L_{f}$ is given by [9]:

$$
\left[\begin{array}{l}
e_{a} \\
e_{b} \\
e_{c}
\end{array}\right] R_{f}\left[\begin{array}{c}
i_{a} \\
i_{b} \\
i_{c}
\end{array}\right]+L_{f} \frac{\mathrm{d}}{\mathrm{d} t}\left[\begin{array}{c}
i_{a} \\
i_{b} \\
i_{c}
\end{array}\right]+\left[\begin{array}{cc}
v_{a} & \\
v_{b} & v_{c}
\end{array}\right]
$$

where $L_{f}$ and $R_{f}$ are the filter inductance and resistance respectively; $v_{a}, v_{b}$ and $v_{c}$ represent the grid voltage components voltages; $e_{a}, e_{b}$ and $e_{c}$ represent voltages at the inverter output; $i_{a}, i_{b}$ and $i_{c}$ are the line currents. Transformation in the rotating $d-q$ reference frame is calculated as

$$
\begin{aligned}
& \frac{\mathrm{d} i_{q-f}}{\mathrm{~d} t}=\frac{1}{L_{f}}\left(e_{q}-R_{f} i_{q_{-f}}-\omega L_{f} i_{d-f}-v_{q}\right), \\
& \frac{\mathrm{d} i_{d-f}}{\mathrm{~d} t}=\frac{1}{L_{f}}\left(e_{d}-R_{f} i_{d-f}-\omega L_{f} i_{q-f}-v_{d}\right)
\end{aligned}
$$

where $e_{q}$ and $e_{d}$ are the inverter $q$-axis and $d$-axis voltage components respectively. $i_{q-f}$ and $i_{d-f}$ are the $q$-axis current and $d$-axis current of Grid. $v_{d}$ and $v_{q}$ are the grid voltage components in the $d$-axis and $q$-axis voltage components respectively.

The DC-side equation can be given by

$$
\frac{2}{3}\left(C \frac{\mathrm{d} U_{d c}}{\mathrm{~d} t}+i_{d c}\right)=\frac{v_{d}}{U_{d c}} i_{d-f}+\frac{v_{q}}{U_{d c}} i_{q-f}
$$

where $U_{d c}$ and $i_{d c}$ are the DC- bus voltage and DC-bus current respectively.

The instantaneous power is given by

$$
\begin{aligned}
Q & =\frac{3}{2}\left(v_{d} i_{q-f}-v_{q} i_{d-f}\right), \\
P & =\frac{3}{2}\left(v_{d} i_{d-f}+v_{q} i_{q-f}\right) .
\end{aligned}
$$

If the grid voltage space vector $\boldsymbol{u}$ is oriented on $d$-axis, then

$$
v_{d}=V, \quad v_{q}=0 .
$$




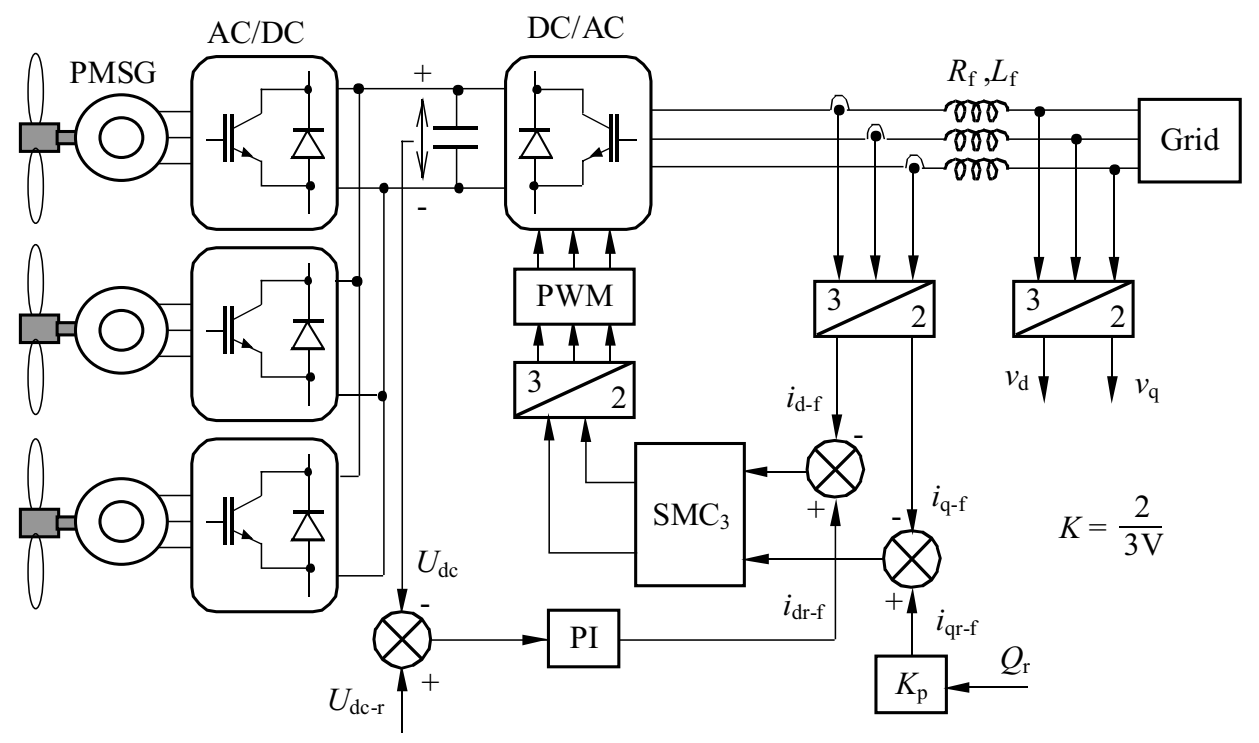

Fig. 10. Schematic of control strategy for WF

Thus, (39-40) may be expressed as

$$
\begin{aligned}
& \frac{\mathrm{d} i_{q-f}}{\mathrm{~d} t}=\frac{1}{L_{f}}\left(e_{q}-R_{f} i_{q-f}-\omega L_{f} i_{d-f}\right), \\
& \frac{\mathrm{d} i_{d-f}}{\mathrm{~d} t}=\frac{1}{L_{f}}\left(e_{d}-R_{f} i_{d-f}+\omega L_{f} i_{q-f}\right) .
\end{aligned}
$$

Then, the reactive power and active power can be expressed as

$$
\begin{aligned}
Q & =\frac{3}{2} V i_{q-f}, \\
P & =\frac{3}{2} V i_{d-f} .
\end{aligned}
$$

Accordingly, reactive and active power control can be achieved by controlling quadrature and direct current components, respectively. Moreover, the aim of the control of the grid side, is to transfer all the active power produced by the PMSGs to the grid and also to produce no reactive power so that unity power factor is obtained. As a result, the DC-link voltage must remain constant. The d-axis reference current is determined by DC-link voltage controller in order to control the converter output real power. For the power converter, there are two closed-loop controls. The fast dynamic is associated with the line current control in the inner loop where the nonlinear SM control is adopted to track the line current control. While, in the outer loop, slow dynamic is associated with the DC voltage control. Furthermore, the PI controller is employed so as to generate the reference source current $i_{d r-f}$ and regulate the DC voltage, but the reference signal of the $q$-axis current $i_{q r-f}$ is produced by the reactive power $Q_{r}$ according to (47).

Let us introduce the following sliding surface for $i_{d-f}$ and $i_{q-f}$

$$
\begin{aligned}
& S_{d-f}=i_{d r-f}-i_{d-f}, \\
& S_{q-f}=i_{q r-f}-i_{q-f} .
\end{aligned}
$$

where $i_{d r-} f$ and $i_{q r-f}$ are the desired value of $d$-axis current and $q$-axis current, respectively. Moreover, $i_{d r-f}$ is produced by the loop of DC-bus control and the reference signal of the $q$-axis current $i_{q r-f}$, is directly given from the outside of the controller and it sets to zero to achieve unity power factor control. It follows that

$$
\begin{aligned}
\stackrel{\bullet}{S_{d-f}}= & \stackrel{\bullet}{i_{d r-f}-} \stackrel{\bullet}{i_{d-f}} \\
& =\stackrel{\bullet}{i_{d r-f}}-\frac{1}{L_{f}}\left(e_{d}-R_{f} i_{d-f}+\omega L_{f} i_{q-f}-V\right)
\end{aligned}
$$

$$
\begin{aligned}
S_{q-f}^{\bullet}=i_{q r-f} & -i_{q-f}^{\bullet} \\
& =i_{q r-f}-\frac{1}{L_{f}}\left(e_{q}-R_{f} i_{q-f}-\omega L_{f} i_{d-f}\right)
\end{aligned}
$$

when the sliding mode occurs on the sliding surface, then

$$
\begin{aligned}
& S_{d-f}=\stackrel{\bullet}{S_{d-f}}=0, \\
& S_{q-f}=\stackrel{\bullet}{S_{q-f}}=0 .
\end{aligned}
$$

In order to obtain commutation around the surface and good dynamic performances, the control includes two terms [19]

$$
U_{c}=u_{e q}+u_{n}
$$

where $u_{e q}$ is an equivalent control input that determines the system's behaviour on the sliding surface. Furthermore, it is the estimated equivalent control which is used to compensate the unknown system dynamics. So, during the sliding mode and in permanent regime, $u_{e q}$ is calculated from (53) and (54). In addition, $u_{n}$ is used so as to guarantee the attractiveness of the variable to 
Instantenous wind speed $(\mathrm{m} / \mathrm{s})$

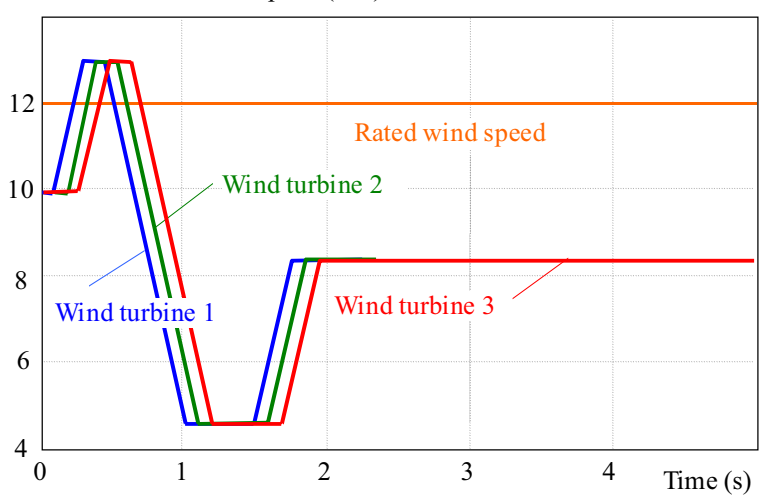

Fig. 11. Instantaneous wind speeds $(\mathrm{m} / \mathrm{s})$

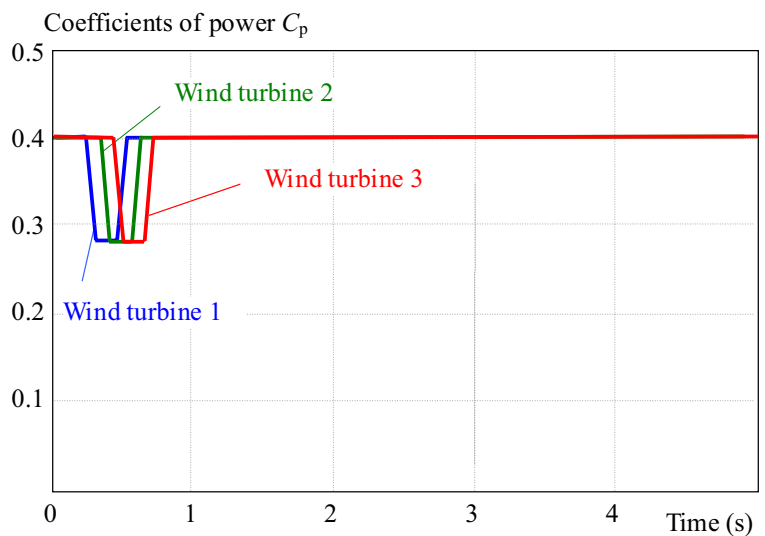

Fig. 13. Variation of coefficients of power

be controlled towards the commutation surface. It maintains the state on the sliding surface in the presence of the parameter variations and disturbances. Then

$$
u_{n}=k_{\delta} \operatorname{sgn}\left(S_{\delta-f}\right)
$$

where $k_{\delta} \succ 0$ and $\delta$ is $d$ or $q$.

Combining (45), (46) and (49)-(54) the controls voltage of $d$ axis and $q$ axis are defined by

$$
\begin{gathered}
v_{d r-f}=L_{f} i_{d r-f}+R_{f} i_{d-f}-L_{f} \omega i_{q-f} \\
+V+k_{d-f} \operatorname{sgn}\left(S_{d-f}\right), \\
v_{q r-f}=R_{f} i_{q-f}+L_{f} \omega i_{d-f}+k_{q-f} \operatorname{sgn}\left(S_{q-f}\right)
\end{gathered}
$$

where $k_{d-f} \succ 0$ and $k_{q-\mathrm{f}} \succ 0$.

Furthermore, nonlinear control SM is a discontinuous control. So as to reduce the chattering, the continuous function as exposed in (59) where $\operatorname{sgn}\left(S_{\omega}\right)$ is a sign function defined as [20]

$$
\operatorname{sgn}= \begin{cases}1, & S_{\omega} \succ \varepsilon, \\ \frac{S_{\omega}}{\varepsilon}, & \varepsilon>\left|S_{\omega}\right|, \\ -1 & -\varepsilon \succ S_{\omega},\end{cases}
$$

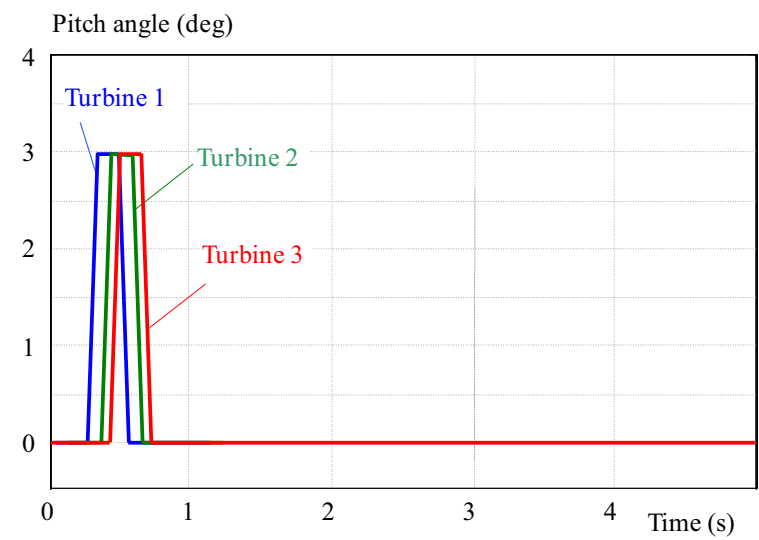

Fig. 12. Pitch angles of wind turbines

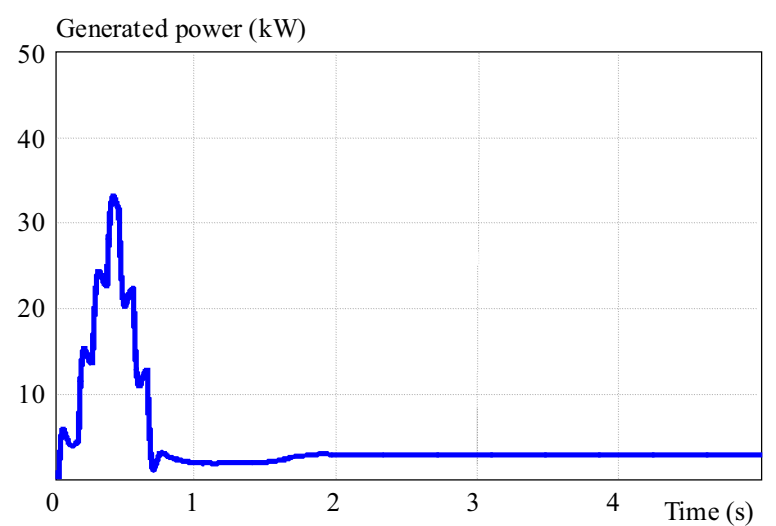

Fig. 14. Total generated power (W)

$\varepsilon$ is a small positive number. If the $\varepsilon$ is too small or too large, the dynamic quality of the system will be reduced. After that, the value of $\varepsilon$ should be chosen vigilantly.

Theorem 1. If the Dynamic sliding mode control laws are designed as (57) and (58) then the global asymptotical stability of (39) and (40), is ensured.

P r o of . In order to determine the existence condition of the sliding mode, it's required to design the Lyapunov function. We define the following function, including the $q$ axis current and the $d$ axis current as

$$
\Upsilon_{f}=\frac{1}{2} S_{d-f}^{2}+\frac{1}{2} S_{q-f}^{2}
$$

From Lyapunov stability theory, to guarantee the attraction of the system throughout the surface and the sliding manifold is reached after a limited time, $\Upsilon_{f}$ can be derived that

$$
\dot{\Upsilon}_{f} \prec 0
$$

By differentiating the Lyapunov function (60), we obtain

$$
\dot{\Upsilon}_{f}=S_{d-f} \dot{S}_{d-f}+S_{q-f} S_{q-f}^{\bullet}
$$




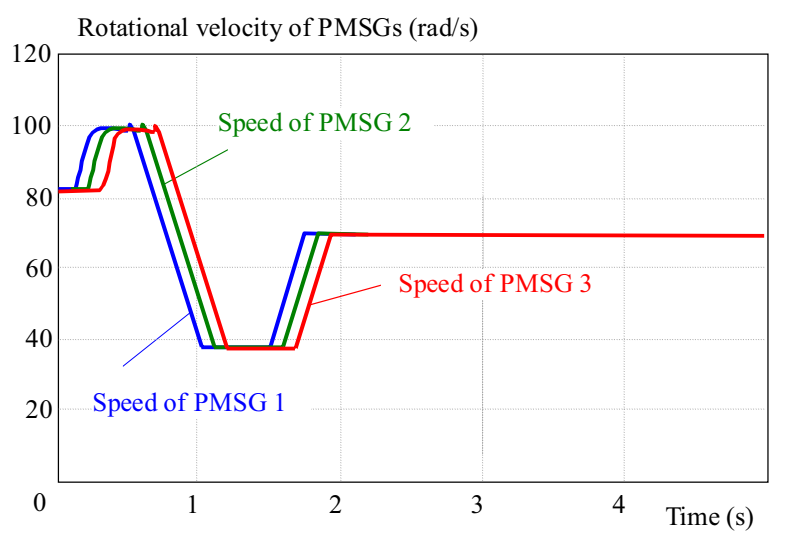

Fig. 15. Speeds of PMSGs

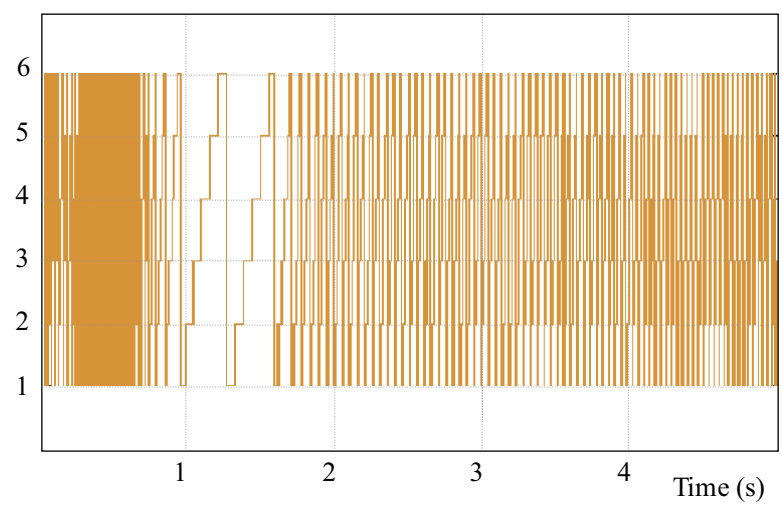

Fig. 17. Sector

and hence

$$
\begin{gathered}
\dot{\Upsilon}_{f}=-\frac{1}{L_{f}}\left(e_{d}-R_{f} i_{d-f}+\omega L_{f} i_{q-f}-V\right) S_{d-f} \\
-\frac{1}{L_{f}}\left(e_{q}-R_{f} i_{q-f}-\omega L_{f} i_{d-f}\right) S_{q-f} \\
=-\mu_{d-f} S_{d-f}^{2}-\mu_{q-f} S_{q-f}^{2} \\
-\frac{1}{L_{f}}\left(e_{d}-R_{f} i_{d-f}+\omega L_{f} i_{-f}-V-\mu_{d-f} L_{f} S_{d-f}\right) S_{d-f} \\
-\frac{1}{L_{f}}\left(e_{q}-R_{f} i_{q-f}-\omega L_{f} i_{d-f}-\mu_{q-f} L_{f} S_{q-f}\right) S_{q-f}
\end{gathered}
$$

Then, with (57) and (58) the following inequality is satisfied

$$
\dot{\Upsilon}_{f}=-\mu_{d-f} S_{d-f}^{2}-\mu_{q-f} S_{q-f}^{2} \prec 0
$$

Where $\mu_{d-f} \succ 0$ and $\mu_{q-f} \succ 0$.

Accordingly, the asymptotic stability in the current loop is guaranteed and the DC-bus voltage control tracking is achieved.

Finally, PWM is used so as to produce the control signal. The structure of the DC-link voltage and that of the current controllers for grid-side converter is depicted in Fig. 10.

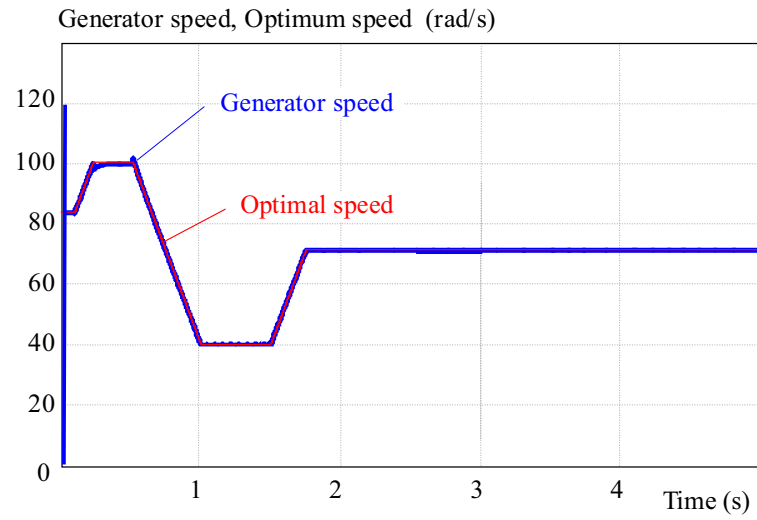

Fig. 16. Speed of PMSG1(rd/s)

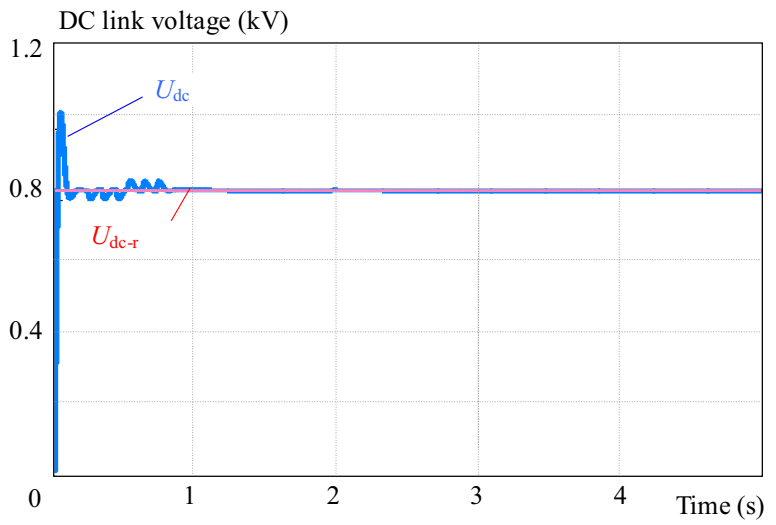

Fig. 18. DC link voltage

\section{SIMULATION RESULTS}

his paragraph presents the simulated responses of the WF under variable wind speed. The parameters of PMSGs used are given in Table 2. The $30 \mathrm{KW}$ wind farm consists of 3 PMSGs based $10 \mathrm{KW}$ generators connected to a common DC-bus. The block diagram of WF is shown in Fig. 11. Furthermore, during the simulation, for the grid side inverter, the $q$ axis command current, $i_{q r-f}$, is set to zero. Simulation results are given in Figs. 1119. Figures 11-16 show the waveforms of wind speeds, pitch angles, coefficients of power conversion, total power generated and rotors angular velocities of the WF, respectively. It can be seen, for each turbine, that when the wind speeds increase, the rotor angular velocity increases proportionally too and the power coefficient will drop to maintain the rated output power. So, the WF operates under MPPT control. Moreover, the initial pitch angle $\beta$ keeps the value of $0^{\circ}$, the tip speed ratio $\lambda$ maintains the optimal value 8.1 , and the power coefficient $C_{p}$ is the maximum around 0.41 . Although, when the wind speed is up the rated wind speed $\left(v_{n}=12 \mathrm{~m} / \mathrm{s}\right)$, the operation of the pitch angle controllers is actuated and the pitch angle $\beta$ is increased. This has for consequence decreasing power coefficient $C_{p}$, for each WTG. Accordingly, the tip speed ratios are decreasing. The pitch angles rise to lower the extracted wind power. Consequently, rotational 
Table 2. Parameters of the power synchronous generators

\begin{tabular}{cc}
\hline Parameter & Value \\
\hline$P_{r}$ rated power & $10(\mathrm{~kW})$ \\
$\omega_{m}$ rated mechanical speed & $100(\mathrm{rd} / \mathrm{s})$ \\
$R$ stator resistance & $0.05(\Omega)$ \\
$L_{q}, L_{d}$ stator $d$-axis and $q$-axis inductance & $0.635 \mathrm{~m}(\mathrm{H})$ \\
$\psi_{f}$ permanent magnet flux & $0.192(\mathrm{~Wb})$ \\
$p_{n}$ pole pairs & 4 \\
\hline
\end{tabular}
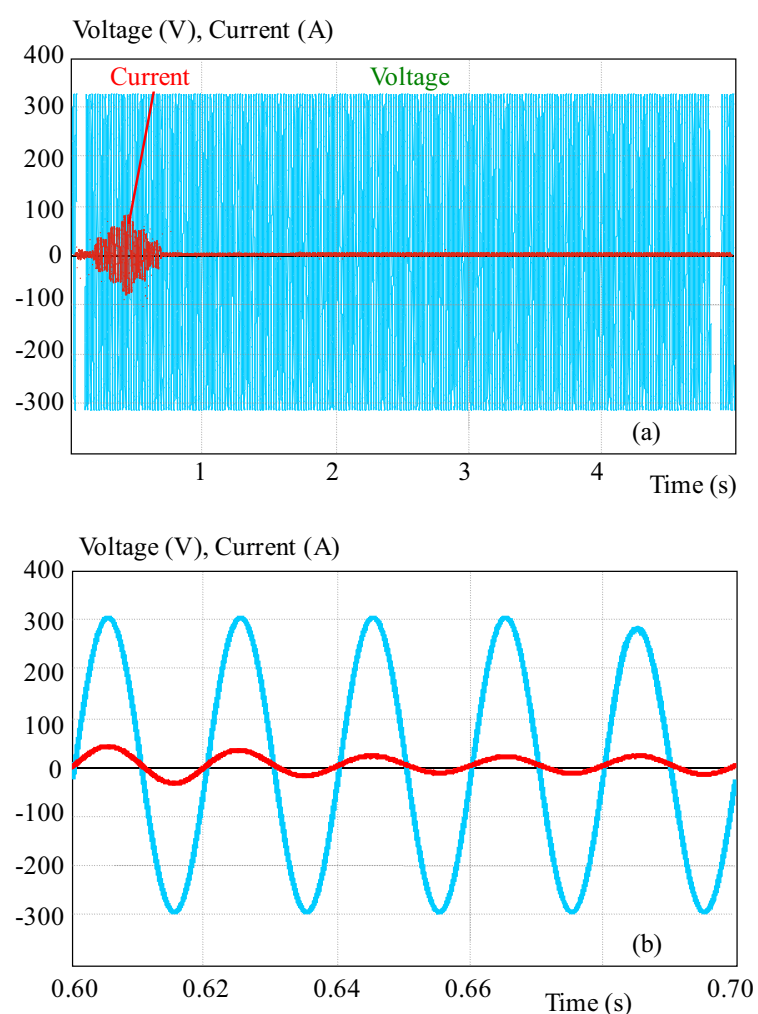

Fig. 19. The waveforms of three phase current and voltage of GRID

speeds and power extracted are keeping constants. Besides, aerodynamic power is optimized with MPPT strategy and kept at his nominal value when the wind speed exceeds the nominal value. The total power extracted is shown in Fig. 14. The results show variation in the power extracted when the incoming winds are different for each turbine generator. In addition, because all the turbines are working at their optimum level, and if the wind speeds are up the rated wind speed, the power generated reaches its maximum level. Figure 16 shows the optimum speed and the rotor angular speed of PMSG1. It is seen that the speed follows the reference quite well. As a result, speeds of PMSGs are adjusted. Figure 17 presents the sector in which the stator flux, for PMSG1, is located. Figure 18 shows the simulation result of DC link voltage that remains a constant value. This proves the effectiveness of the established regulators. Figure 19 shows the variation and a closer observation of three phase current and voltage of GRID. The frequency imposed by the grid is $50 \mathrm{~Hz}$. It is obvious that unity power factor is achieved approximatively. The simulation results demonstrate that the control strategies show very good dynamic and steady state performance and work very well.

\section{CONCLUSIONS}

This paper has presented a new control approach of a WF with variable speed PMSGs. Each PMSG of the WF is connected to the DC-bus through a rectifier, but the DC-bus is connected to the grid through only one DC/AC inverter. The control algorithm combines the technique of DTC to regulate the speeds of PMSGs and SM nonlinear control theory to sustain the DC-bus voltage and regulate the grid-side power factor. The algorithm of MPPT has been used in terms of the adjustment of the PMSGs rotor speeds according to instantaneous wind velocity and limitation by Pitch angle strategy for high wind speeds. Consequently, each generator can operate at speed independently of the speed of other generator. Under different wind conditions, Simulation results have been tested. As a result, WF system with the PMSGs can not only capture the maximum wind power, but also can maintain the frequency and amplitude of the output voltage with unity power factor. The employed control strategy provides an optimal control solution for wind energy conversion systems based on the PMSGs.

\section{REFERENCES}

[1] PARASTAR, A.-SEOK, J. K. : High-Gain Resonant SwitchedCapacitor Cell-Based DC/DC Converter for Offshore Wind Energy Systems, IEEE Transactions on Power Electronics 30 No. 2 (Feb 2015), 644-656.

[2] FENGJI LUO-KE MENG-ZHAO YANG DONG-YU ZHENG-YINGYING CHEN-KIT PO WONG : Coordinated Operational Planning for Wind Farm With Battery Energy Storage System, IEEE Transactions on Sustainable Energy 6 No. 1 (Jan 2015), 253-262.

[3] CHEn, J.-JIE, C.-CHUNYING, G. : New Overall Power Control Strategy for Variable-Speed Fixed-Pitch Wind Turbines within the Whole Wind Velocity Range, IEEE Transactions on Industrial Electronics 60 No. 7 (July 2013), 2652-2660.

[4] ALShiBAnI, S.-AGELIDIS, V. G.-DUTTA, R. : Lifetime Cost Assessment of Permanent Magnet Synchronous Generators for MW Level Wind Turbines, IEEE Transactions on Sustainable Energy 5 No. 1 (Jan 2014), 10-17.

[5] ERRAMI, Y.-OUASSAID, M.-MAAROUFI, M.: Variable Structure Control for Permanent Magnet Synchronous Generator Based Wind Energy Conversion System Operating under Different Grid Conditions, Complex Systems (WCCS), 2014 Second World Conference on, 10-12 Nov 2014, pp. 340, 345, doi: 10.1109/ICoCS.2014.7060996.

[6] SHUN YANG-LIDA ZHANG: Modeling and Control of the PMSG Wind Generation System With a Novel Controller, IEEE International Conference on Intelligent System Design and Engineering Applications, Jan 2013, pp. 946-949.

[7] BLAABJERG, F.-KE MA: Future on Power Electronics for Wind Turbine Systems, IEEE Journal of Emerging and Selected Topics in Power Electronics 1 No. 3 (Sep 2013), 139-152.

[8] ERRAMI, Y.-OUASSAID, M.-MAAROUFI, M.: Control of Grid Connected PMSG Based Variable Speed Wind Energy 
Conversion System, International Review on Modelling and Simulations 5 No. 2 (Apr 2012).

[9] ERRAMI, Y.-MAAROUFI, M.-OUASSAID, M. : A MPPT Vector Control of Electric Network Connected Wind Energy Conversion System Employing PM Synchronous Generator, Renewable and Sustainable Energy Conference (IRSEC), 2013 International, 7-9 March 2013, pp. 228-233, doi: 10.1109/IRSEC.2013.6529721.

[10] ERRAMI, Y.-BENCHAGRA, M.-HILAL, M.-MAAROUFI, M.-OUASSAID, M. : Control Strategy for PMSG Wind Farm Based on MPPT and Direct Power Control, Multimedia Computing and Systems (ICMCS), 2012 International Conference on, 10-12 May 2012, pp. 1125-1130, doi: 10.1109/ICMCS.2012.6320210.

[11] DEPENBROCK, M.: Direct Self-Control of Inverter Fed Machine, IEEE Transaction on Power Electronics 3 No. 4 (Oct 1988), 420-429.

[12] RAHMAN, M. F.-ZHONG, L.-LIM, K. W.: A Direct Torque-Controlled Interior Permanent Magnet Synchronous Motor Drive Incorporating Field Weakening, IEEE Transactions on Industry Applications 34 No. 6 (Nov/Dec 1998), 1246-1253.

[13] FU, M.-XU, L. : A Sensorless Direct Torque Control Technique for Permanent Magnet Synchronous Motors, 1999 IEEE IAS Annual Meeting Conference Record, vol. 1, Oct 1999, pp. 159-164.

[14] ERRAMI, Y.-BENCHAGRA, M.-HILLAL, M.-OUASSAID, M.-MAAROUFI, M.: MPPT Strategy and Direct Torque Control of PMSG Used for Variable Speed Wind Energy Conversion System, International Review on Modelling and Simulations 5 No. 2 (Apr 2012).

[15] NOGUCHI, T.-TOMIKI, H.-KONDO, S.-TAKAHASHI, I. : Direct Power Control of PWM Converter without PowerSource Voltage Sensors, IEEE Transactions on Industry Applications 34 No. 3 (May/Jun 1998), 473-479.

[16] ESCOBAR, G.-STANKOVIC, A. M.-CARRASCO, J. M.GALVAN, E.-ORTEGA, R.: Analysis and Design of Direct Power Control (DPC) for a Three Phase Synchronous Rectifier via Output Regulation Subspaces, IEEE Transactions on Power Electronics 18 No. 3 (May 2003), 823-830.

[17] UTKIN, V. I. : Sliding Mode Control Design Principles and Applications to Electrical Drives, IEEE Transactions on Industrial Electronics 40 No. 1 (Feb 1993).

[18] BELTRAN, B.-AHMED-ALI, T.-BENBOUZID, M. E. H. : Sliding Mode Power Control of Variable-Speed Wind Energy Conversion Systems, IEEE Transactions on Energy Conversion 23 No. 2 (June 2008), 551-558.

[19] VAlenciagA, F.-PUleston, P. F. : High-Order Sliding Control for a Wind Energy Conversion System based on a Permanent Magnet Synchronous Generator, IEEE Transactions on Energy Conversion 23 No. 3 (Sep 2008), 860-867.

[20] SHAOJING WEN-FENGXIANG WANG: Sensorless Direct Torque Control of High Speed PMSM Based on Variable Structure Sliding Mode, Proceedings of Electrical Machines and Systems, ICEMS-IEEE, International Conference on, 2008, pp. 995-998.

Received 30 July 2012
Youssef Errami received his Agrgation Diploma in Electrical Engineering from Ecole Normale Suprieure de lEnseignement Technique (ENSET), Rabat, Morocco in 2001 and DESS from Laboratory of Physical, Chouab Doukkali University, Eljadida- Morocco, in 2005. In 2009, he joined Electric Machines Laboratory at the Department of Electrical Engineering of Mohammadia Schools of Engineers, Rabat, Morocco. In 2013, he received his $\mathrm{PhD}$ in Electrical Engineering. He is currently a Professor at Faculty of Science, Chouaib Doukkali University, Eljadida, Morocco. Prof. Errami is member of Laboratory: Electronics, Instrumentation and Energy (LEIE)- Team: Exploitation and Processing of Renewable Energy (EPRE)- Physical Department, Faculty of Sciences. His research interests are in the areas of renewable energy, power electronics systems, electric drives and power systems. He is a member of the IEEE.

Mohammed Ouassaid received his Diplme dagrgation in Electrical Engineering from Ecole Normal Suprieur de lEnseignement Technique,Rabat, in 1999, and MScA and $\mathrm{PhD}$ degrees in Electrical Engineering from Ecole Mohammadia dIngnieur, Universit Mohamed V, Rabat, Morocco, in 2002 and 2006, respectively. He is currently a Professor at Mohammadia School's of Engineers, University Mohammed V, Rabat, Morocco. His research interests are electric drives, power electronics, power systems and renewable energy. He is a member of the IEEE.

Mohamed Cherkaoui was born in Marrakech, Morocco in 1954. He received the Engineer Degree in Electrical Engineering, from Mohammedia Engineering School (EMI), Rabat, Morocco, in 1979. He received his PhD degree from Institut National Polytechnique de Lorraine, Nancy, France in 1985. In 1986, he joined the University of Caddi Ayyad in Merrakech as a researcher professor. In 1995, he moves then to the Mohammedia Engineering School (EMI), Rabat, as a professor of higher education and head of Electrical Engineering Department. Prof. Cherkaoui is a director of the research laboratory in electrical power and control of the Mohammedia engineering school (EMI), Rabat,Morocco. He is also an expert with Moroccan ministry for higher education and with industrialists to matters related to the energetic efficiency. His main research interests are renewable energy and control of electrical systems.

Mohamed Maaroufi received his Diplme dingnieur dtat degree from the Ecole Mohammadia, Rabat, Morocco, in 1979 and $\mathrm{PhD}$ degrees from the Lige University, Belgium, in 1990 in Electrical Engineering. In 1990, he joined the Department of Electrical Engineering, Ecole Mohammadia, Rabat, Morocco, where he is currently Professor and University Research Professor. His current research interests include electrical network, renewable energy, motor drives and power systems. 